\title{
Формы миграции химических элементов в радоновых водах месторождения «Горводолечебница» (г. Новосибирск)
}

Корнеева Т.В. ${ }^{1}$, Новиков Д.А. ${ }^{1,2}$

${ }^{1}$ Институт нефтегазовой геологии и геофизики им. А.А. Трофимука СО РАН, Новосибирск, KorneevaTV@ipgg.sbras.ru

${ }^{2}$ Новосибирский национальный исследовательский государственный университет, Новосибирск

Аннотация. Впервые приводятся результаты изучения форм миграции элементов в радоновых водах месторождения «Горводолечебница» (юг Западной Сибири). Показана ведущая роль системы водапорода в этих процессах. На месторождении развиты радоновые воды преимущественно гидрокарбонатного кальциевого и гидрокарбонатного кальциево-магниевого состава с величиной общей минерализации от 144 до 1741 мг/дм ${ }^{2}(22 \mathrm{Rn}=163.2-1276.5$ Бк/дм³). Результаты расчета миграционных форм и индексов насыщения относительно основных породообразующих минералов с использованием программных комплексов WATEQ4f и Visual Minteq 3.0 показали, что элементы мигрируют преимущественно в виде свободных катионов, гидрокарбонатных, карбонатных форм и гидроксокомплексов. Установлено, что воды, с общей минерализаций до 600 мг/дм³ являются ненасыщенными по отношению к карбонатным минералам. С ростом общей минерализации от 600 до 1800 мг/дм³ наблюдается увеличение индексов насыщения, что приводит к пересыщению подземных вод относительно арагонита, кальцита и доломита. Не наблюдается насыщения вод относительно гипса и ангидрита. Выявлена степень насыщения радоновых вод ферригидритом, частично гриналитом, сидеритом, а также в единичных случаях тальком.

Ключевые слова: микроэлементы, радоновые воды, формы миграции, индексы насыщения, месторождение радоновых вод «Горводолечебница», город Новосибирск, Западная Сибирь.

\section{Migration Forms of chemical elements in radon waters of the Gorvodolechebnitsa field, Novosibirsk}

\author{
Korneeva T.V. ${ }^{1}$, Novikov D.A. ${ }^{1,2}$ \\ ${ }^{1}$ Trofimuk Institute of Petroleum Geology and Geophysics of SB of RAS, KorneevaTV@ipgg.sbras.ru \\ ${ }^{2}$ Novosibirsk State University
}

\begin{abstract}
Results obtained in the investigation of the forms, in which the elements migrate in radonrich waters of the Gorvodolechebnitsa field (the southern part of West Siberia), are reported for the first time. The leading part of the water - rock system in these processes is demonstrated. Radon-rich waters mainly with calcium hydrocarbonate and calcium-magnesium hydrocarbonate composition, with total mineralization 166 to $\left.1555 \mathrm{mg} / \mathrm{dm}^{3}{ }^{222} \mathrm{Rn}=163.2-1276.5 \mathrm{~Bq} / \mathrm{dm}^{3}\right)$ are developed at the field. Results of the calculations of migration forms and saturation indices with respect to the major rock-forming minerals involving software packages WATEQ4f and Visual Minteq 3.0 showed that the elements migrate mainly in the form of free cations, hydrocarbonate, carbonate forms and hydroxo complexes. It was revealed that waters with total mineralization up to $600 \mathrm{mg} / \mathrm{dm}^{3}$ are unsaturated with respect to carbonate minerals. With an increase in total mineralization from 600 to $1800 \mathrm{mg} / \mathrm{dm}^{3}$, an increase in saturation indices is observed. This causes groundwater supersaturation with respect to aragonite, calcite and dolomite. No water saturation with respect to gypsum and anhydrite is observed. The degree of saturation of radon-rich waters with ferrihydrite, partially with greenalite, siderite, and with talc in isolated instances was revealed.

Keywords: microelements, radon waters, distributions forms, saturation indices, Gorvodolebnitsa radon field, Novosibirsk, Western Siberia.

Радоновые воды имеют широкое распространение на Земле с максимальными к настоящему времени концентрациями радона до 182000 Бк/дм³ (Duenas et al., 1998; Horvath et al., 2000; Bohm, 2002; Gurler et al., 2010 и др.). Ранее в научной литературе отмечалось, что Новосибирские радоновые воды в России являются наименее изученными (Гусев, Вериго, 1984). История их изучения связана с широкомасштабными поисками на уран в Центральной Сибири, которые были начаты еще в 1945 году СУ «Енисейстрой» МВД СССР и открытием затем Березовской экспедицией Пригородного месторождения в окрестностях города Новосибирска (Долгушин, Царук, 2015).
\end{abstract}




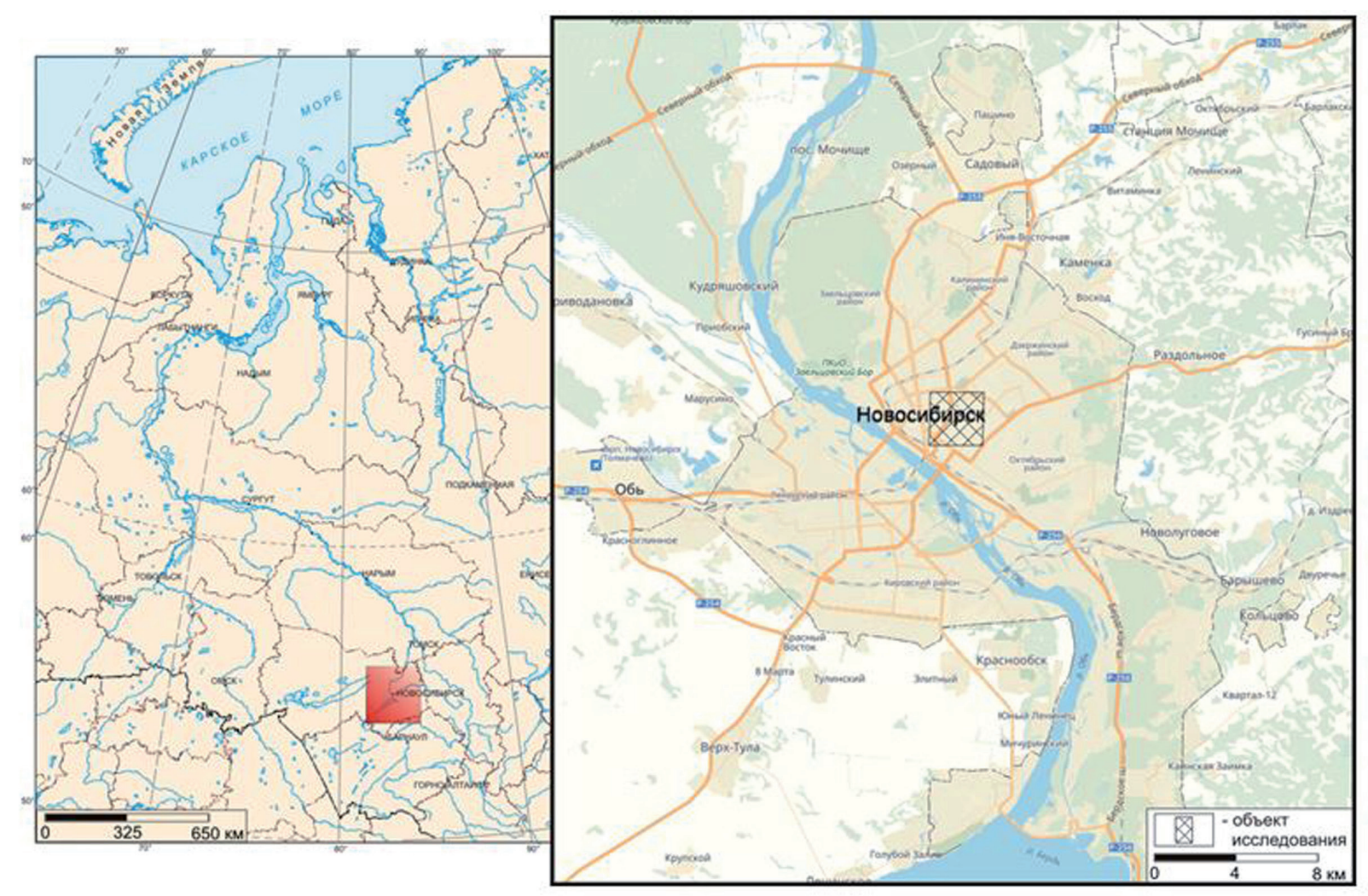

Рис. 1. Местоположение района исследований.

Fig. 1. Location of the study region.

Месторождение «Горводолечебница» расположено в густо застроенном Центральном районе города Новосибирска (рис. 1) и приурочено к одноименному массиву верхнепалеозойских гранитов, залегающих на глубинах около 50 метров. Трещинно-жильные воды относятся преимущественно к гидрокарбонатному кальциевому типу (по классификации С.А. Щукарева) кислородно-азотных слабоминерализованных (до 1741 мг/дм³) холодных вод с концентрацией радона до 1276.5 Бк/дм³. В гидрогеологическом разрезе, как и в целом города Новосибирска, можно выделить два водоносных комплекса (Новиков и др., 2018; Сухорукова, Новиков, 2018). Первый объединяет четвертичные отложения, а второй - породы палеозойского фундамента. Такие гидрогеологические условия часто развиты в прибортовых районах артезианских бассейнов (Novikov, Sukhorukova, 2015; Novikov, 2017).

Воды четвертичных отложений пресные, с величиной общей минерализации 344-1841 мг/дм³, по показателю $\mathrm{pH}$ (6.9-8.0) воды относятся к нейтральным и слабощелочным. Содержание радона в воде находится в диапазоне 163-389 Бк/дм³. Установлено два обогащенных радоном источника, разгружающихся в долине реки Каменка: родник №1 и колодец №2, в которых концентрации радона достигают 389 Бк/дм³ и 229 Бк/дм³ соответственно. Химический тип воды четвертичных отложений относится к гидрокарбонатно-хлоридному кальциевому типу. К водонасыщенным зонам экзогенной и тектонической трещиноватости верхнепалеозойских гранитов приурочены минеральные радоновые воды, которые характеризуется нейтральными и слабощелочными значениями рН от 6.8 до 7.8. Воды гидрокарбонатного кальциевого состава относятся к пресным с величиной общей минерализации, изменяющейся в интервале 144-1741 мг/дм³. Концентрация радона в палеозойских гранитах на месторождении варьирует в пределах от 1075 до 1216 Бк/дм³.

В микроэлементном составе повышены содержания (мкг/дм³): $\mathrm{Sr}$ до 10580, Mn до 2100, Ва до 1260, Со до 200, Ті до 110, Мо до $88, \mathrm{Ni}$ до $32, \mathrm{Cu}$ до 11, Ве до 1.1. С ростом общей минерализации в растворе также накапливаются микроэлементы (мкг/дм³): $\mathrm{Cr}$ до 6.7 и $\mathrm{Ag}$ до 0.2. Для сравнения в изученном ранее Заельцовском месторождении радоновых вод расположенном северо-западнее 

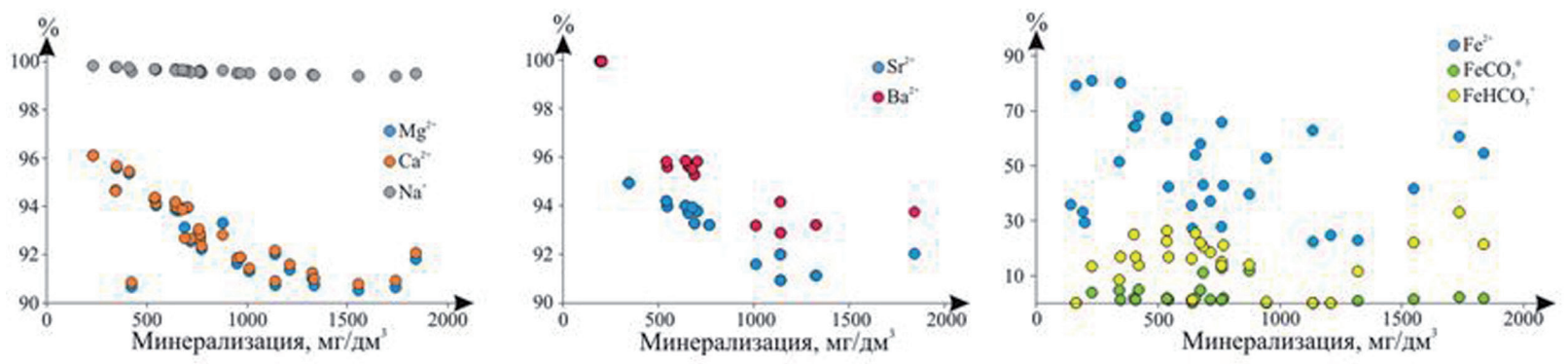

Рис. 2. Зависимость форм миграции элементов от общей минерализации.

Fig. 2. Dependence of the elements migration forms on total mineralization.

от района исследований концентрации ряда микроэлементов значительно ниже и составляют (мкг/дм³): Sr до 4700, Mn до 1300, Мо до 31, Ni до 9.7 и т.д. (Корнеева, Новиков, 2018; Новиков и др., 2019; Novikov, Korneeva, 2019).

Гидрогеохимические условия радоновых вод, сложившиеся в пределах месторождения «Горводолечебница», определили основные формы нахождения элементов в растворе - простые катионные, гидрокарбонатные, карбонатные и гидроксокомплексы (рис. 2). С увеличением обшей минерализации, простые катионные формы $\mathrm{Mg}^{2+}, \mathrm{Ca}^{2+}, \mathrm{Na}^{+}, \mathrm{Sr}^{2+}, \mathrm{Ba}^{2+}$ уменьшаются. Так как содержания бария (2 класс опасности) в некоторых пробах превышают значения ПДК в 2-6 раз, а его свободная катионная форма нахождения наиболее подвижна, то этот элемент способен мигрировать на большие расстояния, попадать в поверхностные воды. Формы бериллия (1 класс опасности) представлены в виде нейтрального гидроксокомплекса $\mathrm{Be}(\mathrm{OH})_{2}(98.8 \%)$, а его концентрация также превышает ПДК в 5.5 раз. В радоновых водах Fe(II) не имеет строгой зависимости от минерализации и формы его нахождения представлены в виде $\mathrm{Fe}^{2+}, \mathrm{FeHCO}_{3}{ }^{+}, \mathrm{FeCO}_{3}{ }^{0}$. $\mathrm{Fe}(\mathrm{III})$ мигрирует в форме двух гидроксокомплексов $\mathrm{Fe}(\mathrm{OH})_{2}{ }_{2}^{+}$и $\mathrm{Fe}(\mathrm{OH})_{3}{ }^{0}$.

Марганец, так же, как и железо (II) мигрирует в основном в форме свободных ионов и в меньшей степени в форме карбонатных и гидрокарбонатных комплексов. Химические формы миграции тяжелых металлов никеля и меди представлены в виде карбонатных $\left(\mathrm{NiCO}_{3}{ }^{0}, \mathrm{CuCO}_{3}{ }^{0}\right)$ и гидрокарбонатных $\left(\mathrm{NiHCO}_{3}{ }^{-}, \mathrm{CuHCO}_{3}^{-}\right)$комплексов, свободных катионов $\left(\mathrm{Ni}^{2+}, \mathrm{Cu}^{2+}\right)$. Помимо вышеупомянутых форм миграции, для меди характерна также нейтральная гидроксидная форма нахождения $\mathrm{Cu}(\mathrm{OH})_{2}^{0}$ (рис. 3). В немногочисленных пробах, содержащих серебро, расчетные формы миграции этого благородного металла представлены различными хлоридными комплексами $\mathrm{AgCl}^{0}, \mathrm{AgCl}_{2}^{-}$и свободными ионами $\mathrm{Ag}^{+}$.

Полученные результаты по формам миграции химических элементов позволяют дать прогнозную оценку по направленности процессов аутигенного минералообразования в системе вода - порода. Зависимость значений индексов насыщения минеральных фаз относительно величины минерализации вод для карбонатных минералов (кальцит, доломит и арагонит) и сульфатных минералов (ангидрит и гипс) показаны на рисунке 4. Установлено, что воды, с общей минерализаций до 600 мг/дм³ являются ненасыщенными по отношению к карбонатным минералам, что ранее отмеча-

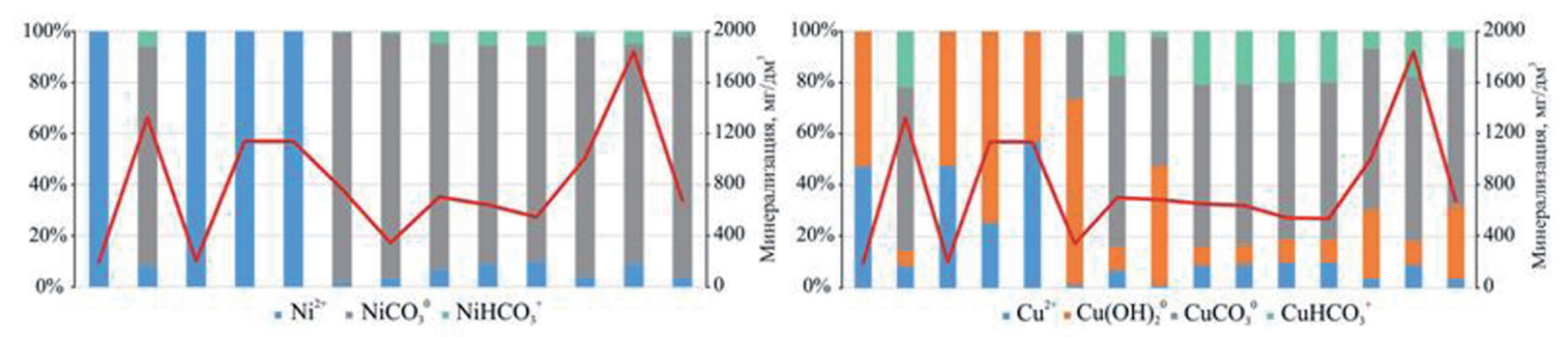

Рис. 3. Формы миграции никеля и меди

Fig. 3. Ni and $\mathrm{Cu}$ migration forms. 


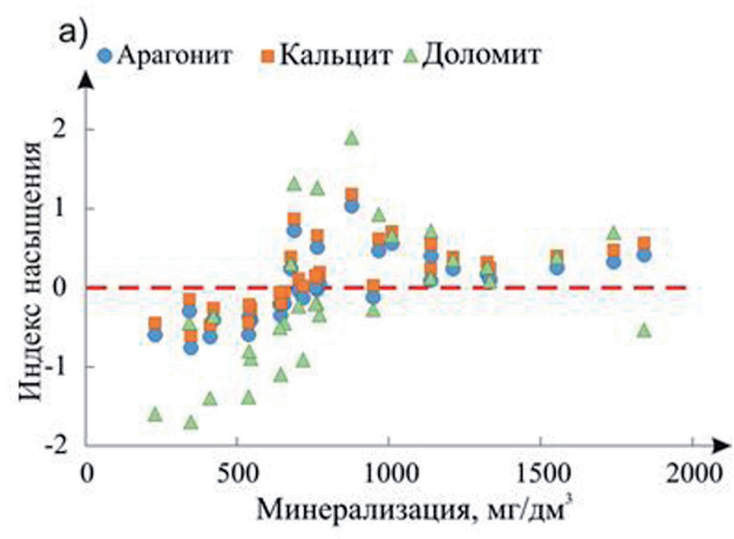

B)

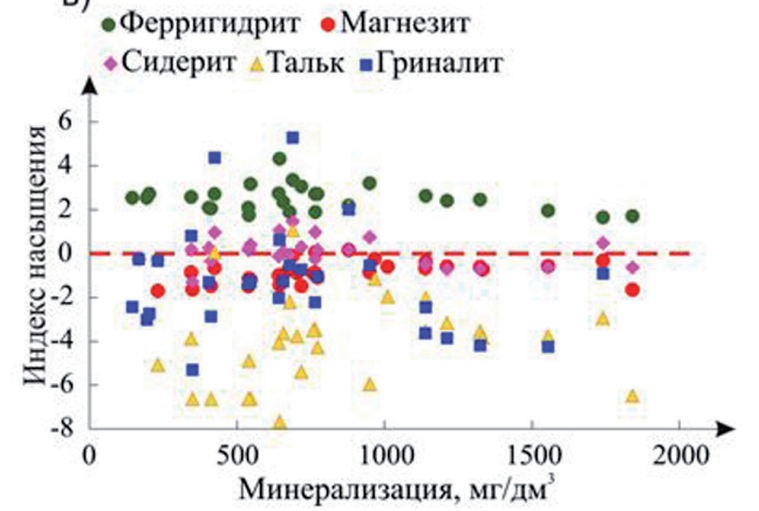

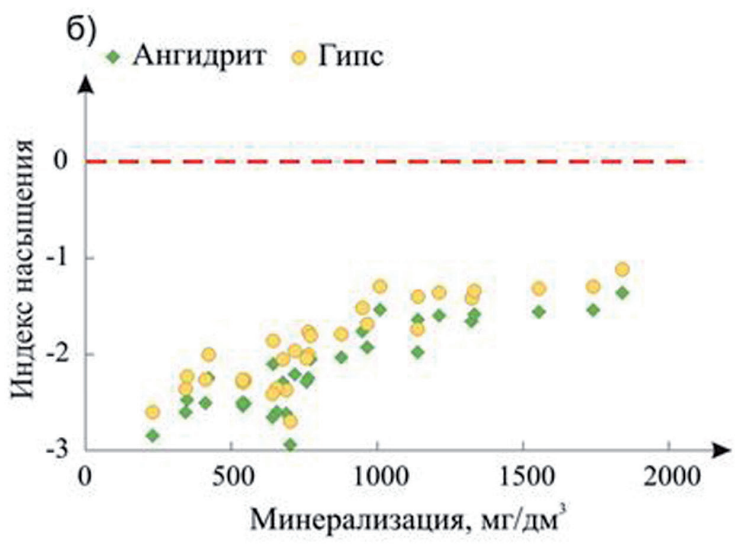

Рис. 4. Индексы насыщения радоновых вод к ряду минеральных фаз относительно их общей минерализации.

Fig. 4. Saturation indices of radon waters to different mineral phases relative to their total mineralization.

лось С.Л. Шварцевым для вод зоны гипергенеза (Шварцев, 1996). С ростом общей минерализации от 600 до 1800 мг/дм³ наблюдается увеличение индексов насыщения, что приводит к пересыщению подземных вод относительно арагонита, кальцита и доломита.

Карбонатные минералы, как правило, являются реакционноспособными, и результаты геологоразведочных работ указывают на их наличие в водовмещающих отложениях (Росляков и др., 2001). Следовательно, наиболее вероятная интерпретация заключается в том, что карбонатные и алюмосиликатные минералы находились в контакте с подземными водами в течение длительного периода времени. Это указывает на то, что конгруэнтное растворение карбонатных минералов и гидролиз алюмосиликатов играет первостепенную роль во вкладе $\mathrm{Ca}^{2+}, \mathrm{Mg}^{2+}$ и $\mathrm{HCO}_{3}^{-}$в радоновых водах месторождения «Горводолечебница». Очевидно, что и инконгруэнтное растворение алюмосиликатных минералов также оказывало существенное влияние на высвобождение этих ионов.

Железо- и магнийсодержащие минеральные фазы в радоновых водах не имеют строгой зависимости с их минерализацией. Так, повсеместно воды пересыщены относительно ферригидрита, и частично гриналита, сидерита, а также в единичных случаях талька, что может приводить к их осаждению из раствора. Значения индексов насыщения магнезита колеблются в области равновесия, однако при величинах общей минерализации вод от 500-1000 мг/дм³ наблюдается их рост, что может сопровождаться процессами аутигенного минералообразования.

Индексы насыщения гипса и ангидрита также увеличиваются с ростом минерализации вод, при этом пересыщения не достигается, что указывает на отсутствие растворимых сульфатных минеральных фаз в водовмещающих породах. Поэтому логичным продолжением исследований по направленности процессов в системе вода - порода будет детальное литолого-минералогическое изучение вмещающих пород, в первую очередь аутигенных минералов.

Исследования проводились при финансовой поддержке проекта ФНИ № 0331-2019-0025 и Российского фонда фундаментальных исследований и Правительства Новосибирской области в рамках научного проекта № 19-45-540004. 


\section{Литература}

1. Гусев В.К., Вериго Е.К. Радоновые воды Колывань-Томской складчатой зоны, их использование и охрана // Изменение природных условий под влиянием деятельности человека. 1984. С. 99-107.

2. Долгушин А.П., Царук И.И. Урановорудный потенциал Центрально-Сибирского региона // Разведка и охрана недр. 2015. № 10. С. 28-34.

3. Корнеева Т.В., Новиков Д.А. Механизмы накопления микроэлементов в радоновых водах Заельцовского месторождения (юг Западной Сибири) // Материалы Всероссийского совещания по подземным водам Востока России. Новосибирск. Изд-во: ИПЦ НГУ. 2018. С. 270-276.

4. Новиков Д.А., Сухорукова А.Ф., Корнеева Т.В. Гидрогеология и гидрогеохимия ЗаельцовскоМочищенского проявления радоновых вод (юг Западной Сибири) // Геодинамика и тектонофизика. 2018. T. 9. № 4. C. 1255-1274. DOI: 10.5800/GT-2018-9-4-0394.

5. Новиков Д.А., Деркачев А.С., Сухорукова А.Ф. Гидрогеохимия Заельцовско-Мочищенского проявления радоновых вод // Интерэкспо Гео-Сибирь. 2019. Т. 2. № 1. С. 125-132. DOI: 10.33764/2618-981X2019-2-1-125-132.

6. Росляков Н.А., Щербаков Ю.Г., Алабин Л.В., Нестеренко Г.В., Калинин А.Ю., Рослякова Н.В., Васильев И.П., Неволько А.И., Осинцев С.Р. Минерагения области сочленения Салаира и КолываньТомской складчатой зоны. Новосибирск. Изд-во: СО РАН, филиал «Гео». 2001. 243 с.

7. Сухорукова А.Ф., Новиков Д.А. Гидрогеология Заельцовско-Мочищенского проявления радоновых вод (г. Новосибирск) // Материалы Всероссийского совещания по подземным водам Востока России. Новосибирск: ИПЦ НГУ. 2018. С. 473-480.

8. Шварцев С.Л. Общая гидрогеология. М. Изд-во: Недра. 1996. 423 с.

9. Bohm C. Radon in Wasser-Uberblick fur den Kanton Graubunden // Jahresbericht Naturforschende Gesellschaft Graubunden. 2002. V. 111. P. 49-79.

10. Duenas C., Fernandez M.C., Enraquez C., Carretero J., Liger E. Natural radioactivity levels in Andalusian spas // Water Research. 1998. V. 32 (8). P. 2271-2278. DOI: 10.1016/S0043-1354(97)00472-7.

11. Gurler O., Akar U., Kahraman A. Measurements of radon levels in thermal waters of Bursa, Turkey // Fresenius Environmental Bulletin. 2010. V. 19 (12). P. 3013-3017.

12. Horvath A.D., Bohus L.O., Urbani F., Marx G., Piroth A., Greaves E.D. Radon concentrations in hot spring waters in northern Venezuela // Journal of Environmental Radioactivity. 2000. V. 47(2). P. 127-133. DOI: 10.1016/S0265-931X(99)00032-6.

13. Novikov D.A. Hydrogeochemistry of the Arctic areas of Siberian petroleum basins // Petroleum Exploration and Development. 2017. V. 44 (5). P. 780-788. DOI: 10.1016/S1876-3804(17)30088-5.

14. Novikov D.A., Sukhorukova A.F. Hydrogeology of petroleum deposits in the northwestern margin of the West Siberian Artesian Basin // Arabian Journal of Geosciences. 2015. V. 8 (10). P. 8703-8719. DOI: 10.1007/ s12517-015-1832-5.

15. Novikov D.A., Korneeva T.V. Microelements in radon waters of the Zaelsovsky field (the southern part of West Siberia) // Journal of Physics: Conference Series. 2019. P. 012096. DOI: 10.1088/1742-6596/1172/1/012096. 